\title{
Coordination of the Industrial Relocation and the Cultural and Creative Industries in the Post-industrial Age in Beijing
}

\author{
Xi Wang, Mei-Chen Fu \\ School of Land Science and Technology, China University of Geosciences, Beijing, China \\ E-mail: wangxi60@163.com, fumeichen@163.com
}

\begin{abstract}
In the past decades population growth, urban rural gap, air pollution and other problems have become increasingly obvious in the process of over speedy urbanization of Beijing. Beijing has urgent demands for the sustainable development of industries and shaping new city pattern. This paper discusses the necessity and feasibility of industrial relocation in Beijing and the value of cultural and creative industries to Beijing's urban regeneration. The conclusions are that (1) industrial relocation drives decentralization of population in central urban area of Beijing and contributes to the conservation of the old downtown and the industrial heritage; (2) promoting the cultural and creative industries has both the economic and social value and is an important strategy of urban regeneration of Beijing after industrial relocation.
\end{abstract}

Keywords-Industrial relocation; Decentralization of population; Cultural and creative industry; Beijing

\section{INTRODUCTION}

Beijing has been in rapid urbanization since the 1990s. The urbanization rate of Beijing has reached $86.2 \%$, which is two times that of Hebei. Urbanization not only served the economic development and the urban construction, but resulted in serious environmental $[1,2]$ and social problems. Industry clusters in Beijing create jobs and attract a great amount of migrant workers to Beijing to get employment, which has directly cause the excessive population growth in Beijing in the last two decades. Within the fifth ring road, according to the statistics, the permanent population was 10.536 million by the end of 2014, which makes up 49.0 percent of the total population of Beijing, and the permanent population density is about 15800person $/ \mathrm{km}^{2}$. The maldistribution of population has been partly caused by the maldistribution of industries. The traffic congestion and environmental pollution produced by overcrowded industries trigger the demand for industrial relocation.

Industrial relocation in Beijing contains relocation from inner city to suburban and from Beijing to other cities and aims at promoting industrial upgrading and development of the suburban and the surrounding cities. Beijing has been in post-industrial age and is confronted with urban regeneration while relocating industries. The key points of Beijing's urban regeneration are constructing new economy structure, setting up a livable environment and conserving cultural characteristics of Beijing.

Cities have always functioned in part as centers of creativity and cultural production and many cultural and creative industries gather in cities [3,4]. The Cultural and creative industries have an increasingly significant role in societies and economies [5], and their development plays a significant role in landscapes reconstruction and urban regeneration $[6,7]$ and correlates with development of suburban [8]. Since Beijing is the cultural and technological innovation center of China, promoting the cultural and creative industries is necessary to the urban regeneration of Beijing.

The data sources of this paper are the Beijing Statistical Yearbook [9], and Beijing Economic Census Yearbook [10].

\section{NECESSITIES AND FEASIBILITY OF INDUSTRIAL RELOCATION IN BEIJING}

\section{A. Maldistribution and Rapid Growth of Population in Beijing}

Beijing consists of capital core functional area,urban function extension area, new area of urban development and ecological conservation area. Beijing's permanent population reached 21.516 million by the end of 2014, 59.3 percent of which resided in capital core functional area and urban function extension area. The average population density of these two areas was 9327 person $/ \mathrm{km} 2$ while that of new area of urban development was only 1008 person $/ \mathrm{km} 2$. Permanent migrant population of Beijing has been increasing since 1995. Over the period 1990-2014, Beijing's permanent population increased by 10.656 million, 71.8 percent of which were permanent migrant population. By 2014, the permanent migrant population, as the major source of the population growth after 2000 , reached 8.187 million or 38.1 percent of total permanent population in Beijing (Figure 1). 


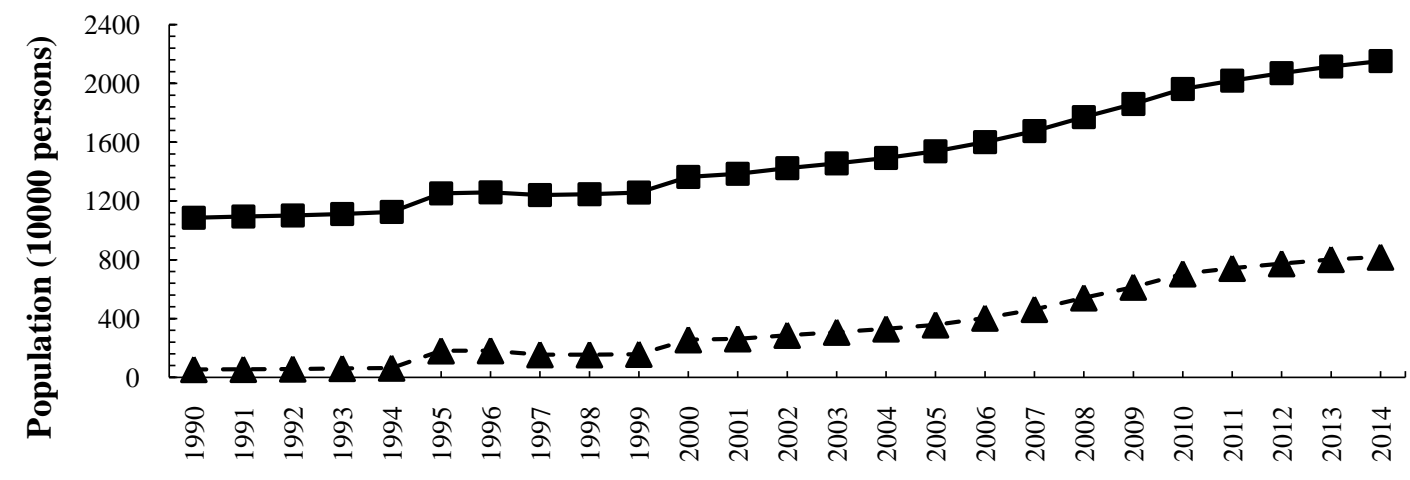

Year

- - Permanent Population $\quad-\triangle-$ Permanent Migrant Population

Figure 1 Population growth in Beijing (1990-2014)

In 2013 the number of legal entities in the central urban area was about 432 thousand, which accounted for 68.6 percent of all in Beijing, and they employed nearly 8 million people or 71.8 percent of all employees in Beijing. In view of the maldistribution and overmuch and speedy concentration of population, Beijing government sets population control target that permanent population should not exceed 23 million and the number of residents in central urban area should shrink by 15 percent by 2020 . To achieve this target, two aspects should be emphasized: limiting the population growth by government authority and stimulating decentralization of population by the industrial relocation.

\section{B. Economical Effect of Industrial Relocation in Beijing}

The value of the secondary industry to Beijing's GDP has been less than the tertiary industry for over 20 years and has been keeping on declining. In 2014 the contribution of the secondary industry to Beijing's economy was 21.4 percent of Beijing's GDP, while the contribution of the tertiary industry was 77.9 percent (Figure 2). Beijing has been in post-industrial age and no longer relies on the secondary industry to develop economy, so the relocation of some manufacturing industries, which are classified as the secondary industry, from Beijing to other cities has not much negative impact on economic growth of Beijing, and also frees land resources for high value added industries, which generates an internal need for the industrial relocation. The secondary industry is still an important component of Tianjin's and Hebei's economy. Tianjin is superior in port transportation and advanced manufacturing industry while Hebei is rich in space and natural resource. Both Tianjin and Hebei are able to admit industries relocated from Beijing, which generates a favorable external environment for the industrial relocation.

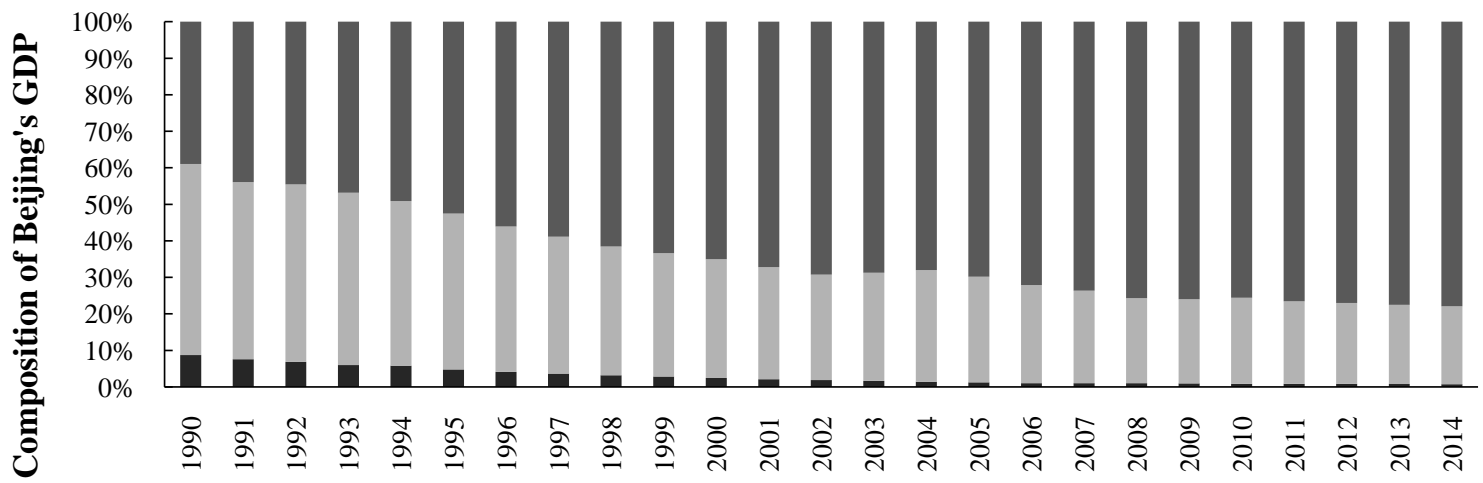

Year

- Primary Industry $\quad \square$ Secondary Industry $\quad$ Tertiary Industry

Figure 2 Composition of Beijing's GDP. 


\section{APPROACHES TO PROMOTING INDUSTRIAL RELOCATION}

Promoting industrial relocation in Beijing aims at changing the current comprehensive industrial structure and monocentric urban pattern of Beijing, turning focus on industries that meet the capital functional requirements, facilitating the development of capital's satellite towns and mitigating population pressure and pollution.

Beijing government should introduce strict regulations to restrict industries which don't conform to the capital functional requirements. It is also the government's task to conduct relocation of high energy consuming manufacturing industries and labor intensive industries, with upgrading equipment, in order to achieve energy saving and pollutant reduction. By limiting land supply and implementing policy about differentiating land price and taxation, the land cost in the central urban area of Beijing is raised and the industrial relocation is accelerated by profit incentive.

Not only industries, but public service and administrative organization are over concentrated in the central urban area. There are 91 Class 3A comprehensive hospitals in Beijing, and 76 of them are in the central urban area. Besides, most high quality primary schools are in the central urban area too. The lack of public service such as health service and elementary education in suburban results in that resident in the inner city are not inclined to move to the suburban. Thus it is necessary for Beijing government to decentralize the public service to satellite towns and surrounding cities to enhance their attractiveness to the residents for the purpose of forming a multipolarization pattern around Beijing. In addition, transportation needs to be optimized by building efficient traffic net among Beijing's inner city, suburban, satellite towns and surrounding cities to strengthen their connection.

\section{THE DEVELOPMENT AND PROMOTION OF THE CULTURAL AND CREATIVE INDUSTRIES OF BEIJING}

Beijing is an international modern city with long history and also the hub of politics, culture, international communication and scientific innovation of China. Urban regeneration, in the process of and after industrial relocation, requires substituted industries that conduce to the conservation of Beijing's history, the dissemination of Beijing's culture and the improvement of environmental quality.

\section{A. Development of Cultural and Creative Industries}

Cultural and creative industries can help to improve urban environmental quality, optimize urban industrial structure and enhance urban competitiveness, but its development also needs circumstances such as accumulated culture, cultivation of the creative personnel, cultural infrastructure and space. Beijing possesses the objective basis for promoting cultural and creative industries, because (1) there are rich cultural heritage and historical sites in Beijing, which offer historical and cultural resources;(2) more than 50 universities and a large number of outstanding scientific institutions are impetus for the development of cultural and creative industries;(3) the rapid economic growth and urban construction in recent years lay a firm material foundation for their development.

Cultural and creative products are produced and commercialized in the same way as those of other industries [11] but contain more contents about culture and originality and create more revenue than the others. Cultural and creative industries have been developing speedily and have become the mainstay industry in Beijing. In 2014, the cultural and creative industries contribute 46 billion US dollars, or 13.2 percent of Beijing's GDP, to Beijing's economy and employed 1.9 million people, or 16.6 percent of all employees in Beijing (Table I).

TABLE I. VALUE ADDED AND EMPLOYMENT OF CULTURAL AND CREATIVE INDUSTRY AS A PERCENTAGE OF THE TOTAL OF BEIJING.

\begin{tabular}{cccccccc}
\hline & 2008 & 2009 & 2010 & 2011 & 2012 & 2013 & 2014 \\
\hline Value added & $12.1 \%$ & $12.3 \%$ & $12.0 \%$ & $12.2 \%$ & $12.3 \%$ & $13.0 \%$ & $13.2 \%$ \\
Employment & $10.9 \%$ & $11.5 \%$ & $11.9 \%$ & $13.2 \%$ & $13.8 \%$ & $16.1 \%$ & $16.6 \%$ \\
\hline
\end{tabular}

The cultural and creative industries in Beijing include 9 sectors. Among all these sectors, cultural and arts, transaction of artworks and design service grew faster in value added than the others; except journalism and publications all other 8 sectors grew in employment significantly (Table II). As a whole, the growth of the cultural and creative industries in value added preceded the growth in employment. 
TABLE II. STATISTICS FOR CATEGORY OF CULTURAL AND CREATIVE INDUSTRY.

\begin{tabular}{|c|c|c|c|c|c|}
\hline & \multicolumn{2}{|c|}{$\begin{array}{c}\text { Value Added } \\
\text { [100 million yuan] }\end{array}$} & \multicolumn{3}{|c|}{$\begin{array}{c}\text { Employment } \\
{[10000 \text { persons }]}\end{array}$} \\
\hline & 2008 & 2014 & 2008 & 2014 & Average growth rate \\
\hline Total & 1346.4 & 2826.3 & 107.0 & 191.6 & $10.2 \%$ \\
\hline Culture and Arts & 42.7 & 115.6 & 4.8 & 11.2 & $15.2 \%$ \\
\hline Journalism and Publications & 153.7 & 239.7 & 16.0 & 15.7 & $-0.3 \%$ \\
\hline Radios, Televisions and Movies & 120.1 & 200.3 & 4.6 & 7.2 & $7.8 \%$ \\
\hline Software, Network and Computer Services & 703.1 & 1605.2 & 39.8 & 90.8 & $14.7 \%$ \\
\hline Advertisements and Exhibitions & 112.2 & 220.2 & 9.3 & 17.3 & $10.9 \%$ \\
\hline Transaction of Artworks & 20.5 & 56.2 & 1.7 & 2.7 & $8.0 \%$ \\
\hline Design Services & 52.8 & 127.7 & 7.8 & 16.7 & $13.5 \%$ \\
\hline Tourism and Entertainment & 58.4 & 99.7 & 10.0 & 13.0 & $4.5 \%$ \\
\hline Other Auxiliary Services & 82.9 & 161.7 & 13.0 & 17.0 & $4.6 \%$ \\
\hline
\end{tabular}

The employees of cultural and creative industries mainly concentrate in Haidian, Chaoyang, Xicheng and Dongcheng, largely because (1) there are numerous and complete cultural infrastructures, such as library, museum and theatre, in these four districts; (2) dozens of universities in these four districts, especially in Haidian, provide abundant educational resources, and college students are a huge talent pool for cultural and creative industries; (3) the knowledge spillovers, the common use of cultural infrastructure and the talent pool conduce to the concentration, and employees and creators benefit from knowledge exchange and mutual inspiration that can be seen as positive externalities produced by the concentration.

The principle factors that affect cultural and creative industries are capital support, talent pool, technology, infrastructure, market environment, policy environment, creative environment. Beijing has been in the monocentric development pattern for a long time. As a result, the infrastructure, living environment and job opportunity in the central urban area are superior to those in the suburban. That also to some extent explains the concentration of employees of cultural and creative industries in central urban area.

\section{B. Promoting the Cultural and Creative Industries in Beijing}

Due to the importance of increasing the mass enthusiasm for innovation, it is advisable for the government to take steps to encourage the competent people to participate in the entrepreneurial activities in the field of innovation. Those people who set up small and micro creative enterprises need financial support from the government to them in ways such as reducing loan interest, tax reduction and exemption, and state-owned capital investment. In addition, to create fair and supportive environment for entrepreneurship, the government also need to boost protection of intellectual property rights, provide legal aid and strengthen its service function by rendering convenient consulting and auxiliary services. Taking use of the media to advertise the historical culture of Beijing, the high quality service of Beijing government and the prospect of development of the cultural and creative industries in Beijing is a good choice to attract the creative talents, both at home and abroad, to expand their career in
Beijing.

Beijing lacks world famous cultural brand currently. The historical and cultural heritages in Beijing are precious property and are significant in attracting and fostering the talented people for the cultural and creative industries. Beijing should take full advantage of the existing cultural and creative clusters, the rich historical and cultural heritage in Dongcheng and Xicheng and the famous scenic spots in suburban to build a world competitive cultural brand in the field of culture and art, transaction of artworks and cultural tourism.

\section{V.DISCUSSION AND CONCLUSION}

Besides accelerating industrial upgrading and spurring development of surrounding cities, industrial relocation has an important function in conserving historical buildings in Beijing. The history of more than 800 years as a capital and the profound cultural heritage endow Beijing with the unique atmosphere of ancient culture and the identity of a historical city. There are a lot of historical buildings, which are tangible cultural heritage and nonrenewable cultural resource, in the old downtown. The old downtown is located in the capital core functional area, which is the most population intensive area, as well as the most gathering area with too many industries, employees and urban functions such as education, medical treatment and business. The overcrowded population and industries bring about serious traffic congestion in the old downtown, and the space requirement of the heavy traffic is in conflict with the protection of the spatial pattern of the old downtown. Moreover, the overmuch urban function in this area hinders the full utilization of the historical culture resource and impedes the development of the cultural and creative industries that rely on the space morphology of the old downtown. Therefore, it is needed to reduce the urban functions in the old downtown area by industrial relocation in order to relieve the stress brought by the overcrowded population, conserve historical buildings, emphasize the historical culture function and develop cultural industries and tourism that accords with the features of the old downtown.

The industrial relocation will leave behind many abandoned factories, some of which could be regarded as 
industrial heritage. The disposal of these industrial heritages ought to be classified according to the value of the buildings and the possibility of reuse. The industrial heritage with historical and artistic value should be conserved and transformed into museums and parks opened to the public for providing entertainment and showing the local industrial history. The abandoned but reusable workshops and warehouse can be rented to small sized enterprises and individuals to develop emerging industries.

Urban development is supported by economic growth, and thus Beijing should develop substituted industries in the process of industrial relocation to maintain economic growth. But in addition to economic growth, urban development also covers creating a favorable living environment. Urban development and economic development should find an equilibrium point that attempts to overemphasize one of them and overlook the other ought to be avoided.

The economic growth of Beijing in recent years lays a firm foundation for the development of the cultural and creative industries and the economy of them will present a more rapid growth compared to Beijing's economy. Beijing should give consideration both to the cultural inheritance and the urban sustainable development in the process of urban regeneration and take advantage of the cultural and creative industries to conserve and reuse the industrial heritage and the old downtown. The cultural and creative industries, which possess economic and social value, not only play an important role in spurring Beijing's economic development, conserving local culture and protecting the environment, but strengthen the urban function of Beijing in the field of culture and innovation. Both the improvement of city environment and the economic development should be taken into account in Beijing's future development. Being a creative city is the future direction of Beijing, and promoting cultural and creative industries contributes to achieving this goal. Beijing's cultural strategies are required to be able to promote the social inclusion, increase the cultural diversity, enhance the cultural inheritability, improve the economy and satisfy the residents' demand for culture.

\section{REFERENCES}

[1] Y. Li, T. Guo, J. Zhou, Study on the development of rural urbanization in Beijing, Procedia Environ. Sci, vol.11, Part B, pp.893-898, 2011.

[2] B. Chen, H. Gong, X. Li, K. Lei, Y. Ke, G. Duan, C. Zhou, "Spatial correlation between land subsidence and urbanization in Beijing, China", Nat. Hazards, vol.75, pp. 2637-2652, 2015.

[3] A. Brown, J. O'Connor, S. Cohen, "Local music policies within a global music industry: cultural quarters in Manchester and Sheffield", Geoforum, vol.31, pp. 437-451, 2000.

[4] N. M. Coe, "The view from out west: embeddedness, inter-personal relations and the development of an indigenous film industry in Vancouver", Geoforum, vol.31, 2000, pp. 391-407, 2000.

[5] E. Pupek, "European creative industry strategies: the dawn of a new public policy", Int. J. Soc. Sci, Humanity, vol.6, 2016, pp. 309-314, 2016.

[6] T. A. Hutton, "Reconstructed production landscapes in the postmodern city: applied design and creative services in the metropolitan core", Urban Geogr, vol. 21, pp.285-317, 2000.

[7] A. C. Pratt, "Urban regeneration: from the arts 'feel good' factor to the cultural economy: a case study of Hoxton, London", Urban Stud, vol.46, pp. 1041-1061, 2009.

[8] C. Collis, E. Felton, P. Graham, "|Beyond the inner city: real and imagined places in creative place policy and practices", Inf. Soc, vol.26, pp.104-112, 2010.

[9] Beijing Municipal Bureau of Statistics, Beijing statistical yearbook, China Statistics Press, Beijing, China, 2015.

[10] Beijing Municipal Bureau of Statistics, Beijing Economic Census Yearbook, China Statistics Press: Beijing, China, 2013.

[11] R. R. Ferrandiz, "Cultural industries in a postindustrial age: entertainment, leisure, creativity, design", Crit. Stud. Media Commun, vol.31, pp. 327-341, 2014. 